Published in: Nature Climate Change 2020 https://doi.org/10.1038/s41558-020-0783-3

\title{
The economic interaction between climate change mitigation, climate migration, and poverty
}

Jochem Marotzke ${ }^{1}$, Dirk Semmann ${ }^{2,3}$, and Manfred Milinski ${ }^{2 *}$

${ }^{1}$ Max Planck Institute for Meteorology, Department 'The Ocean in the Earth System', 20146 Hamburg, Germany. ${ }^{2}$ Department of Evolutionary Ecology, Max-PlanckInstitute of Evolutionary Biology, 24306 Plön, August-Thienemann-Strasse 2, Germany. ${ }^{3}$ present address: Johann-Friedrich-Blumenbach Institut für Zoologie und Anthropologie, Georg-August-Universität Göttingen, 37077 Göttingen, Germany. *Correspondence to email: milinski@evolbio.mpg.de

\begin{abstract}
:
Mitigation of anthropogenic climate change takes place against the backdrop of poor countries being most affected by climate change impacts; climate-induced migration is expected to increase in the future. However, the interaction between mitigation, climate migration, and poverty has not been investigated explicitly. Here we represent simultaneous poverty- and climate-induced migration in a laboratory setting, within the collective-risk social dilemma that arises from attempts to avert dangerous climate change. The relatively rich participants try to prevent migration by the relatively poor, but in the long run these attempts are unsuccessful because of free-riding among the rich. The rich are willing to increase their effort at averting dangerous climate change when the poor are hit by a climate extreme event exacerbating their poverty.

Conversely, the poor are willing to compensate some weaker effort by the rich, as long as the effort by the rich lies above a threshold emerging within the experiment.
\end{abstract}




\section{Main}

While mitigating climate change is a global challenge, climate change impacts through more frequent floods, droughts or heat waves mostly affect poor populations ${ }^{1-4}$. One consequence of these impacts can be forced migration ${ }^{5-7}$. However, migration also occurs for reasons other than climate effects ${ }^{7,15}$. These effects are not unrelated; because poverty is a major driver of people's vulnerability to climate-related shocks and stressors ${ }^{3}$, the flow of people escaping poverty is thus also affected by climate change ${ }^{8}$. To disentangle, for the first time, the interaction of climate- and poverty-induced migration in the context of climate change mitigation is the purpose of this paper.

The theory of migration goes back to Ravenstein's ${ }^{9}$ laws (1885), the last of which stressed the dominance of the economic motive. Although criticized ${ }^{10}$, Ravenstein's paper has stood the test of time and remained the starting point for work in migration theory. To this neoclassical approach Lee ${ }^{11}$ developed a general schema, from which a number of conclusions with regard to the volume of migration, the development of streams and counter-streams, and the characteristics of migrants could be deduced. The new economics of labor migration theory questions some of the ideas and principles considered in the creation of the neoclassic theory ${ }^{12}$. The new approach is being represented by the idea that the emigration decision is not being made only at an individual level, but rather along important human groups, such as families or households ${ }^{13}$. Stark \& Bloom ${ }^{14}$ argue why there was a need for a new theoretical structure to explain international migration. Labor markets were recognized as the main mechanisms that influence international migration. Research on the economics of labor migration has undergone an exciting and significant transformation during the past years ${ }^{12}$. However, climate change is now increasingly enforcing migration. In 2018, approximately 16 million people were displaced by floods, extreme storms, droughts and wildfires ${ }^{7}$.

A common theme in much media, policy and campaign group discourse on climate change is that future environmental change will lead to the further displacement of 
millions of people as 'environmental refugees' or 'environmental migrants ${ }^{\text {'7,15. These }}$ conclusions suffer from the fact that observed migration can be due to causes other than climate change; there are economic, political, demographic, social and other environmental drivers ${ }^{7,15}$. Thus migration plays a key role in the ability of poor households to escape poverty, independent of climate change. Operating in combination these drivers affect individual migration decisions and flows, and the effect of climate change depends on the broad socio-economic context.

Climate change is a slow process, accompanied by extreme events that are expected to increase in frequency and intensity such as floods, heat waves or tropical cyclones, all well-known triggers of displacement ${ }^{7}$. Demographic and environmental factors affect how and whether displaced people return ${ }^{16}$. One of the best-documented longrun effects of rising average surface temperature is its negative effect on productivity in agriculture ${ }^{8}$. Sea level rise as well as a change in tropical storm and cyclone frequency and intensity will lead to an increased risk of coastal flooding and damage ${ }^{15}$. Coastal areas in Bangladesh are projected to be inundated by sea-level rise. Heavy monsoons lead to temporary displacement, but farmers return to their farms with delayed benefits on yields ${ }^{17}$. Land degradation caused by drought as in California, Africa and Asia has affected millions of people, inducing waves of migration $^{7,18}$.

Reports of migrants being rejected by European countries, when they cross the Mediterranean Sea after leaving Africa, are part of the migration debate in Europe $^{7,19,20}$. Climatic conditions, by affecting drought severity and the likelihood of armed conflict, played a significant role as an explanatory factor for asylum seeking in the period 2011-2015 20 . The challenges associated with the large number of arriving refugees have revealed a deep divide among the inhabitants of host countries with economic factors playing a key role in shaping individual refugee helping behaviour ${ }^{19}$. Although costs are a major determinant, it is especially people with a higher degree of prosociality that are willing to bear the personal cost of helping ${ }^{19}$.

Due to the multi-causality of migration, climatic events and conditions typically interact with cultural, economic, political, social and other non-climatic processes that influence migration decision making; the climatic stimulus may be so tightly 
interwoven with other factors that it is difficult to disentangle and isolate ${ }^{7}$. A way out of this dilemma is to simulate essential variables of the natural situation in a laboratory setting using techniques of experimental economics, developed, e.g., by Vernon Smith ${ }^{21}$, with appropriate controls to remove effects of other external influences. Participants in an experimental-economics study are assigned defined roles and are rewarded with the trading profits they earn during the experiment. The benefit of lab experiments is that they reduce the complexity of real-world processes to generate insights that would be difficult to obtain otherwise, and cause-effect relations can be concluded as a 'proof of principle'.

Here we investigate how poverty induces migration from a poor to a rich country, with and without randomly occurring climate events in the poor country, under both overall richer and poorer harvest conditions, and how this affects the prevention of dangerous climate change. We simulate a country that has recently become poor, perhaps because of a lowered ground-water table continuously reducing harvests, and that suffers from frequent heat waves, compared with an unaffected country. Of course, our simulated 'countries' can well be two separate areas within a large country, e.g. Africa. We extend an economic game, the 'collective-risk social dilemma' ${ }^{22-30}$, to study the migratory behaviour of 10 participants per replicate, firstsemester university students, between a poor and a rich country over 20 rounds. Participants could both gain money from the harvest in their local country and invest money into preventing simulated dangerous climate change. Three studies ${ }^{23,24,27}$ using the collective risk social dilemma paradigm exogenously created income inequality, either through assigning differently sized endowments ${ }^{23,27}$, as in the present study, or by automatically enforcing three players to contribute $€ 4$ and the other three $€ 0$ in each of the first 3 rounds in order to create players that were poor because they had already contributed significantly from their endowment to averting climate change and rich players that entered the next 7 rounds with their untouched endowment ${ }^{24}$. Overall, the rich invested a higher proportion of their resources into preventing severe climate change as predicted ${ }^{28}$. However, where enforced payment had preceded the active rounds ${ }^{24}$, the 'poor' paid less only during active rounds, but with enforcement more than the rich. All three studies had no option to migrate. 
Dangerous climate change ${ }^{31}$ might occur when a certain temperature threshold is passed $^{32-34}$. When both rich and poor participants collectively reach the specified target sum of $€ 400$ through individual contributions per round after 20 rounds, simulated dangerous climate change is averted, and all group members are paid out anonymously the money left in their personal account. If they fail to meet the target, they lose all their money with a probability of $90 \%$. From all the money contributed to the climate account, both from groups that met the target and also from groups that failed, an advertisement on 'how to mitigate climate change' was published in one of two German newspapers (see Supplementary Information).

At the start five participants in the rich country have an endowment of $€ 40$ each, five participants in the poor country $€ 20$ each, and the five rich participants earn twice the harvest per round as the five poor before migration has occurred. At most one inhabitant per round can migrate to the other country, at the cost of no harvest in the next round. In both countries the harvest per inhabitant decreases with each immigrant, reaching a Nash equilibrium with same harvest per participant with two inhabitants in the poor and eight in the rich country (Supplementary Table 1). There are two different kinds of scenarios in the present design where Nash equilibrium can be achieved ('Nash Equilibria' in Supplementary Information). Each round consists of the following four steps, always performed in the same order: (1) The inhabitants in each country can posit a wish to migrate. (2) Because governments of many traditional destination countries are placing restrictions on immigration ${ }^{7}$, inhabitants of each country can block immigration if at least four inhabitants invest $€ 0.25$ each towards a target sum of $€ 1.00$, without knowing whether potential immigrants have announced the wish to migrate. If the collective target is met, immigration is blocked for that round, and the attempted migrations expire. (3) All participants are asked to contribute toward climate change mitigation by contributing either $0, € 2$ or $€ 4$ from their endowment to a 'climate account'. (4) Finally, all participants are shown the pseudonyms of all inhabitants, including successful migrants, of each country and individual contributions to the climate account in step (3). Then, the next round starts.

Compared to the control treatment (T0), climate events can occur in the poor country in treatment T1. Climate events represent heat waves, for instance, and happen with a 
probability of either $10 \%$ or $20 \%$ per round in different groups. Once started a climate event lasts for three rounds, during which there is no harvest in the poor country. A third treatment (T2) is the same as T1 except that the harvest per round is twice as high in both the rich and the poor country. Treatment T2 is motivated by the following consideration. Under comparatively poor conditions overall in $\mathrm{T} 0$ and $\mathrm{T} 1$, the rich inhabitants may be motivated to supplement what the poor cannot afford to pay for mitigation, especially during climate events. By contrast, in T2 the rich know that the poor can contribute their share and may hesitate to pay more than the poor (Supplementary Table 1, see Methods for details).

\section{Impact of migration on population size}

Inhabitants of the poor country migrate to the rich country until the Nash equilibrium distribution of eight inhabitants in the rich country and two in the poor country is reached (Fig. 1a,b,c). The number of migration attempts of inhabitants of the poor country is highest in the first round and decreases thereafter in all three treatments (Fig. 1d,e,f). The Nash distribution would have been achieved in round 4 if the rich participants had not invested sufficiently in blocking migration. Thus, the Nash distribution is reached later in all three treatments (Fig. 1a,b,c), after $7.46 \pm 0.72$ rounds in $\mathrm{T} 0$ ( $\mathrm{n}=13$ groups), after $5.71 \pm 0.30$ rounds in $\mathrm{T} 1$ ( $\mathrm{n}=14$ groups), and after $10.50 \pm 1.57$ rounds in T2 ( $\mathrm{n}=14$ groups), each significantly different from four rounds (each $\mathrm{P} \leq 0.002$, Wilcoxon one-sample test).

Each inhabitant in each country could contribute to blocking immigration of a poor participant before a round by investing $€ 0.25$. If at least $€ 1.00$ was invested, migration would be blocked effectively for that round. With $€ 0.75$ or less invested, migration is not blocked, and one migrant is chosen randomly from those that attempt to migrate and arrives in the rich country. The migrant has a migration cost of no harvest in the first round after migration. The number of blockings per round decrease more slowly in T2 than in T1 (Fig. 1g,h,i; mean of rounds 5 to 10, n=14, T2: 0.48, n=14, T1: 0.11, $\mathrm{P}=0.0082, \mathrm{z}=-2.642$. Mann-Whitney U-test), so that the Nash distribution is reached later than in $\mathrm{T} 1(\mathrm{P}=0.019, \mathrm{z}=-2.339$, Mann-Whitney U-test $)$. 

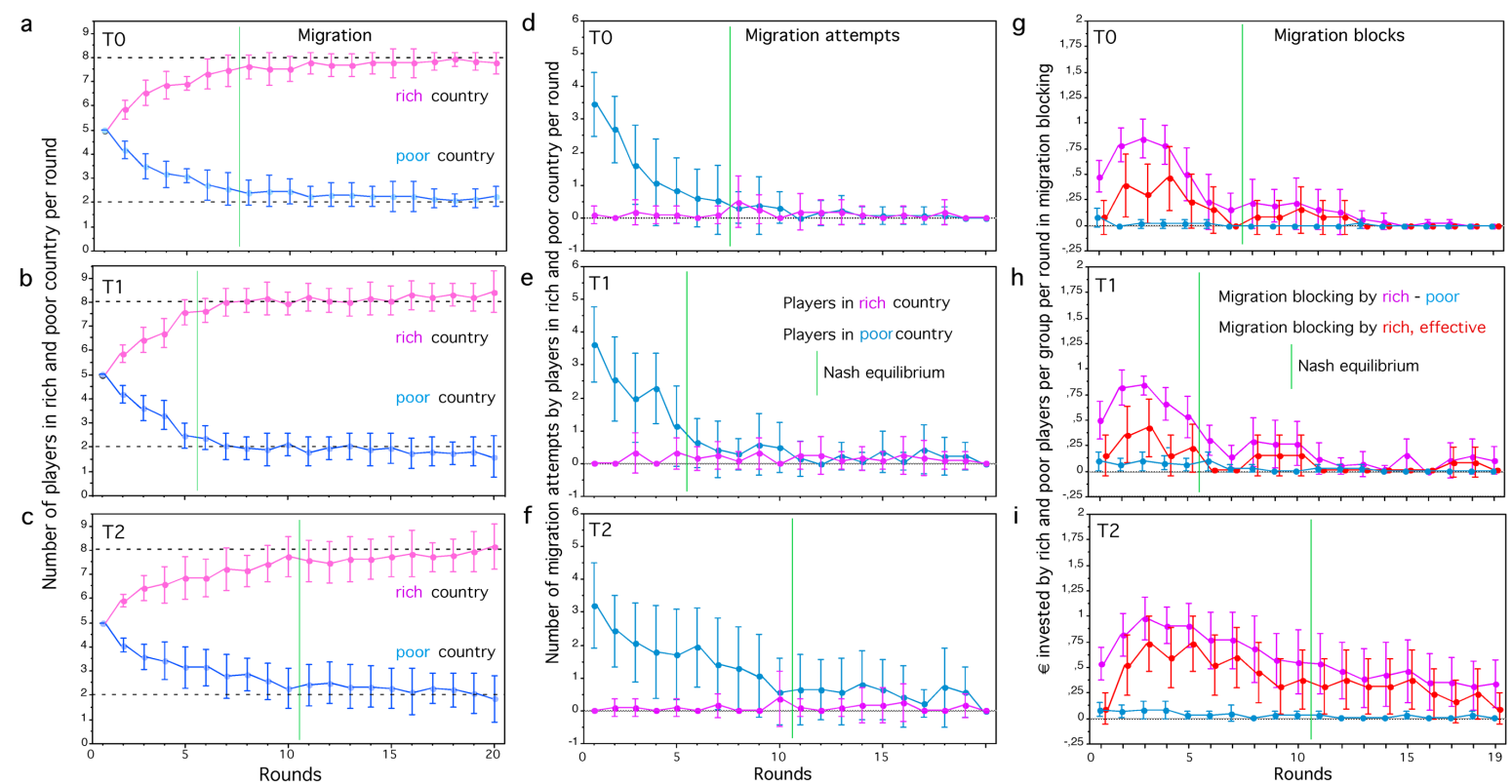

Fig. 1 Migration between rich and poor countries. Top row: T0; middle row: T1; bottom row: T2. Left column $(\mathbf{a}, \mathbf{b}, \mathbf{c})$ : Number (mean \pm s.d.) of inhabitants in rich (pink) and poor (blue) country per group for each round. Stippled lines show numbers of inhabitants corresponding to Nash equilibrium (8 participants in rich country, 2 participants in poor country), green line shows the round when Nash equilibrium is reached on average. Middle column (d, e, f): Migration attempts; mean \pm s.d. per group and round of participants in rich country (pink), in poor country (blue), announced before a round. Right column (g, h, i): Blocking of migration; Euros invested in migration blocking (mean) per group and round, of participants in poor country (blue) and rich country (pink), invested before a round. Effective blocking, at least $€ 1$ invested per round, is shown for rich country (red). Vertical green line shows when the Nash equilibrium is achieved on average.

The difference between total and effective blocking attempts in Fig. 1g,h,i depicts failed blocking attempts that are thus a waste of money. In T1 each rich participant gains $€ 0.25$ if a migrant is blocked for one round (see Supplementary Table 1), exactly what each of the four participants that block effectively invest in blocking and thus corresponding to a net gain of zero. This provides each further rich participant who refuses investment in blocking a net gain of $€ 0.25$. Only if blocking and nonblocking by rich participants alternates among participants across rounds, does each rich participant obtain a net gain. To block or not to block is a 'tragedy of the commons ${ }^{25}$, which invites free-riding and thus leads to rounds with ineffective blocking. In T2 each rich participant gains $€ 0.50$ if migration is blocked for one round, twice the investment in blocking by each of the four participants who block 
effectively. The tragedy of the commons is thus relaxed in T2, producing effective blocking more often (mean \pm s.e.m. per group $2.5 \pm 0.7$ in T0, $1.8 \pm 0.2$ in T1, and 7.1 \pm 1.7 in T2, respectively. $\mathrm{P}$ after Mann-Whitney U-test, $\mathrm{n}_{1}=14, \mathrm{n}_{2}=14, \mathrm{P}=0.003, \mathrm{z}=$ 2.955; Supplementary Fig. 1). However, the tragedy of the commons still exists. Although the rich in T2 have much more money available than those in T1, there is still frequent ineffective blocking. This allows the poor to immigrate, and Nash equilibrium is reached at approximately round 10 .

\section{Climate events}

In both $\mathrm{T} 1$ and $\mathrm{T} 2$ climate events occur randomly, with a probability of $10 \%$ in seven groups in each treatment or $20 \%$ in the other seven groups in each treatment. The actual number of occurrences lies between zero and three events per group. A climate event lasts for three rounds during which there is no harvest income in the poor country; this reduces the expected average harvest. There are significantly more (0.3) inhabitants in the rich country in $\mathrm{T} 1$ in the last five rounds of the game (Fig. 1b, difference to 8: $\mathrm{P}=0.0038$, Wilcoxon one-sample test). There are fewer inhabitants in the poor country during the last five rounds with increasing risk of climate events (mean + s.e.m. $2.17+0.07$ in T0, $1.83+0.19$ in T1 10\%, $1.60+0.11$ in T1 20\%, $\mathrm{P}=0.005, \mathrm{~h}=10.534$, Kruskal Wallis test, Supplementary Fig. 2).

The first climate event after the Nash equilibrium has been reached is now analysed for the behaviour of inhabitants of the rich and poor country in T1 and T2. In Nash equilibrium no poverty migration is expected because the harvest per person is the same in either country, and the pure climate effect on migration can be studied. The number of migration attempts from the poor to the rich country increases significantly $(\mathrm{P}=0.017, \mathrm{z}=-2.389$, Wilcoxon matched pairs test $)$ after the climate event has been announced in round 0 in T1 (Fig. 2a), but not in T2 (Fig. 2d). During a climate event, migration to the rich country incurs no net cost, because there is no harvest in the poor country anyway. The payoff from migrating to the rich country is highest in the first round of the climate event because there is one round of harvesting in the rich country ahead while there is no harvest in the poor country. Consequently, migration attempts decrease during the three rounds of the climate events in T1 and T2. 


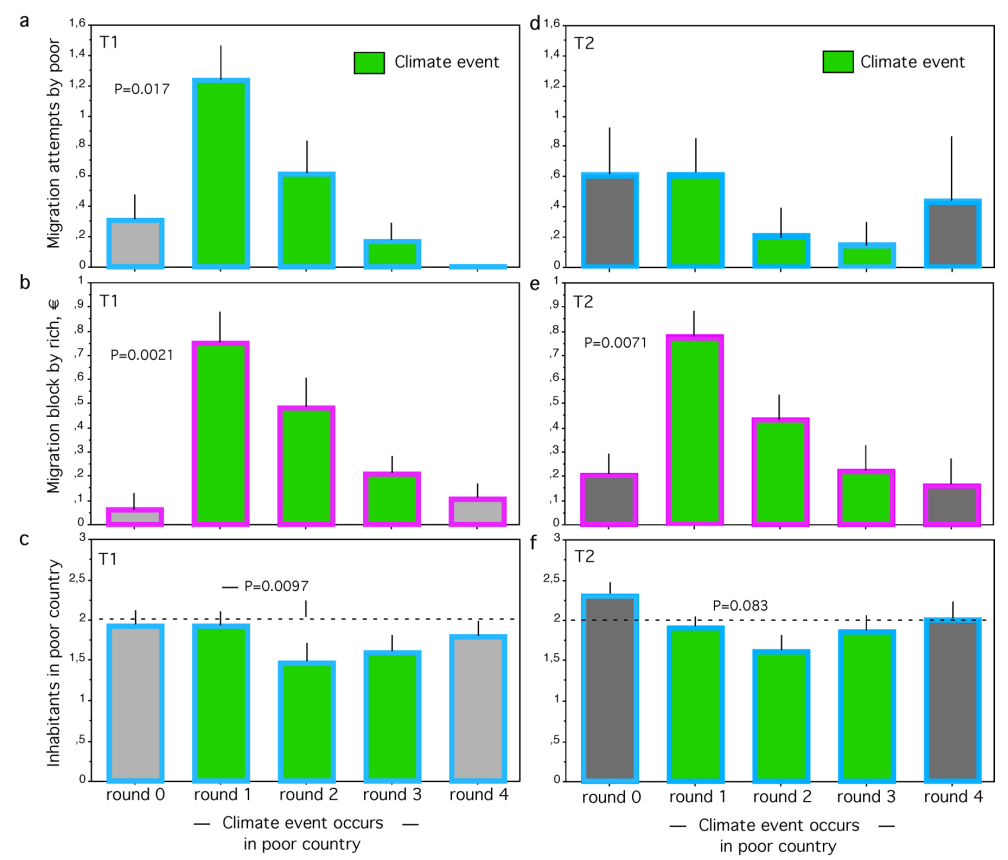

Fig. 2 The course of a climate event. Behaviour of poor and rich participants in the round before, the three rounds during and the round after the first climate event in the poor country after the Nash equilibrium has been reached: there are two participants in the poor and eight participants in the rich country in Nash equilibrium; a. migration attempts (mean + s.e.m.) per group in $\mathrm{T} 0, \mathbf{d}$. in $\mathrm{T} 2$, b. migration block by rich participants $(€)$ per group in T1, e. in T2: c. number (mean + s.e.m.) of inhabitants in the poor country in T1, f. in T2. P after Wilcoxon matched pairs tests, see text. Stippled line depicts number of inhabitants at Nash equilibrium.

The rich inhabitants increase migration blocking pre-emptively (without having observed migration attempts of the poor) and significantly in the first round of the climate event (Fig. 2b, e) in $\mathrm{T} 1(\mathrm{P}=0.0021, \mathrm{~N}=14, \mathrm{z}=-3.072)$ and $\mathrm{T} 2(\mathrm{P}=0.0071, \mathrm{n}=14$, $\mathrm{z}=-2.692$ ). This strong migration blocking hinders successful migration during the first round of the climate event (Fig. 2b, e), and the number of inhabitants in the poor country decreases in the second round of the climate event, significantly in T1 $(\mathrm{P}=0.0097, \mathrm{z}=-2.585$, Fig. $2 \mathrm{c})$ and as a trend in $\mathrm{T} 2(\mathrm{P}=0.083, \mathrm{z}=-1.732$, Fig. $2 \mathrm{f})$. Thereafter investment in migration blocking decreases in both treatments; although only half of the eight participants in the rich country need to invest to block effectively, blocking often fails. The 'richer' rich in T2 (Fig. 2e) invest no more than the 'poorer' rich in T1 (Fig. 2b), even though the rich in T2 gain more from blocking. As a consequence, the number of inhabitants in the poor country builds up again in both treatments until the first round after the climate event, without a lasting effect of the fluctuation. 


\section{Overall economic effects and success}

Only the groups that invest the target sum of $€ 400$ per group, poor and rich participants combined, in the climate account until after round 20, avoid simulated dangerous climate change and receive the money left over in their personal account. If they miss the target they risk losing their money with $90 \%$ probability. The average total investment in climate mitigation lies below the target sum in T0 and T1 and above the target sum in T2 (Fig. 3a); the difference between T1, n=14, and T2, n=14, is significant $(\mathrm{P}=0.0001, \mathrm{z}=-3.970$, Mann-Whitney $\mathrm{U}$-test $)$. Less than $€ 50$ per group, i.e. $€ 3.35$ per participant in $\mathrm{T} 0, € 4.25$ in $\mathrm{T} 1$, are missing to meet the target (Fig. 3a). The percentage of groups that meet the target is low both in T0 (30.8\%) and T1 (21.4\%) but $100 \%$ in T2 (Fig. 3b); the difference between T1 and T2 is significant $(\mathrm{P}=0.0001$, Fisher exact test $)$.

Poor participants in all treatments invest less than $€ 2$ per participant (Fig. 3c, all differences significant, $\mathrm{P}=0.007$ or less, Wilcoxon matched pairs tests). The poor participants in $\mathrm{T} 1$ invest significantly less than the poor participants in $\mathrm{T} 0$, suggesting a climate effect $\left(\mathrm{P}=0.023, \mathrm{z}=\mathrm{z}=-2.282, \mathrm{n}_{1}=13, \mathrm{n}_{2}=14\right.$, Mann-Whitney $\mathrm{U}$ test $)$. By investing significantly more than $€ 2(\mathrm{P}=0.001, \mathrm{z}=-3.297)$, the rich participants in $\mathrm{T} 2$ partly compensate for the lower investment of the poor participants in T2 who, though relatively rich, do not invest significantly more than the poorer poor in $\mathrm{T} 1(\mathrm{P}=0.25$, $\mathrm{z}=-1.149$, Mann-Whitney U-test).

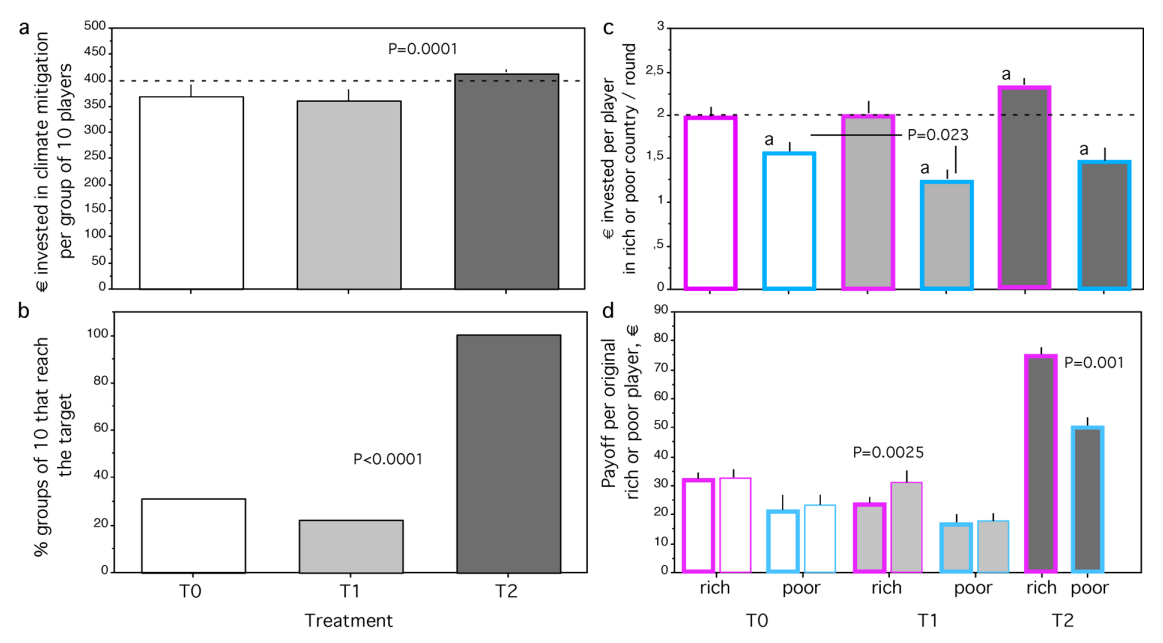


Fig. 3 Investment in climate mitigation and payoff. a. Mean (+ s.e.m.) sum of $€$ invested per group of 10 participants (rich plus poor). Stippled line depicts the target sum of $€ 400$. $\mathbf{b}$. Percentage of groups of 10 participants that reach the target sum of $€ 400$. c. $€$ (mean + s.e.m.) invested per rich and poor participant per group in T0, T1, T2. Stippled line depicts fair share investment of $€ 2$. 'a' shows significant deviation from investment of the fair share of $€ 2$; see text for details. d. Payoff (mean + s.e.m.) of the 5 original rich participants and the 5 original poor participants received per participant in cash at the end of the game if the group reaches the target sum. Columns with thick margin: Results only from those groups that reach the target sum; columns with thin margin: Results only from those groups that do not reach the target sum and thus lose their remaining money. P after Wilcoxon matched pairs test.

Both rich and poor participants in T2 earn much more money than the participants in T0 and T1 (Fig. 3d). The difference between rich and poor participants in T2 $(\mathrm{P}=0.001, \mathrm{z}=-3.296$, Wilcoxon matched pairs test $)$ is slightly bigger than the difference in endowment of $€ 20$ at the start, even though three originally poor participants migrate to the rich country until Nash equilibrium is reached. Note that each migrant takes along their remainder of $€ 40$ or $€ 20$ endowment of their country of origin. The rich participants profit from their longer time in the rich country where they gain higher harvest income until the Nash equilibrium is reached. The difference in payoff between rich and poor participants in $\mathrm{T} 0$ and $\mathrm{T} 1$ is much smaller than the difference in endowment, which shows that the originally rich invest relatively more towards the target sum. Those groups that do not reach the target would have earned more, had they received the money, because they invest less in climate mitigation. The difference is small in both rich and poor participants in $\mathrm{T} 0$ and in poor participants in $\mathrm{T} 1$ but is more pronounced in rich participants in $\mathrm{T} 1$. The difference is $€ 7.6$ in the rich but only $€ 0.9$ in the poor in $\mathrm{T} 1(\mathrm{P}=0.025, \mathrm{z}=-2.245$, Mann-Whitney $\mathrm{U}$ test). The rich are thus mainly responsible for failing to meet the target sum in T1. The difference between total investment in climate mitigation and the target sum is $€ 3.35$ per participant in $\mathrm{T} 0$ and $€ 4.25$ in $\mathrm{T} 1$ (Fig. $3 \mathrm{c}$ ). In both treatments, all participants have much more money left in their account than would be needed to reach the target sum (Fig. 3d).

\section{Economic effect of climate events}


After Nash equilibrium is reached, there is no difference in harvest income per inhabitant between the countries and thus no poverty migration. During the three rounds of the climate event, when there is no harvest income in the poor country, the inhabitants of the poor country decrease their investment in climate mitigation significantly in both T1 and T2 (Fig. 4). The rich do not change their investment in $\mathrm{T} 1$ (Fig. 4a) but in $\mathrm{T} 2$ they increase it (Fig. 4b, $\mathrm{P}=0.017, \mathrm{z}=-2.384$, Wilcoxon matched pairs test). In T1 the poor deviate significantly from the fair share, whereas the rich are close to the fair share but do not compensate the deficit produced by the poor (Fig. $4 \mathrm{c}, \mathrm{P}=0.028, \mathrm{z}=-2.202$, Wilcoxon matched pairs test). In $\mathrm{T} 2$ both the poor and the rich stay close to investing the fair share before and after the climate event, but deviate significantly during the climate event, the poor by producing a significant deficit, the rich by producing a significant overshoot (Fig. 4d). In T1 the poor decrease their investment $(\mathrm{P}=0.028, \mathrm{z}=-2.201)$, whereas the rich tend to increase it $(\mathrm{P}=0.063, \mathrm{z}=$ 1.859, Wilcoxon matched pairs tests). Thus, during the climate event there is a strong decrease of investment by the poor both in T1 and T2 (Fig. 4c, d) but only in T2 a partial compensation by the rich (Fig. 4d).
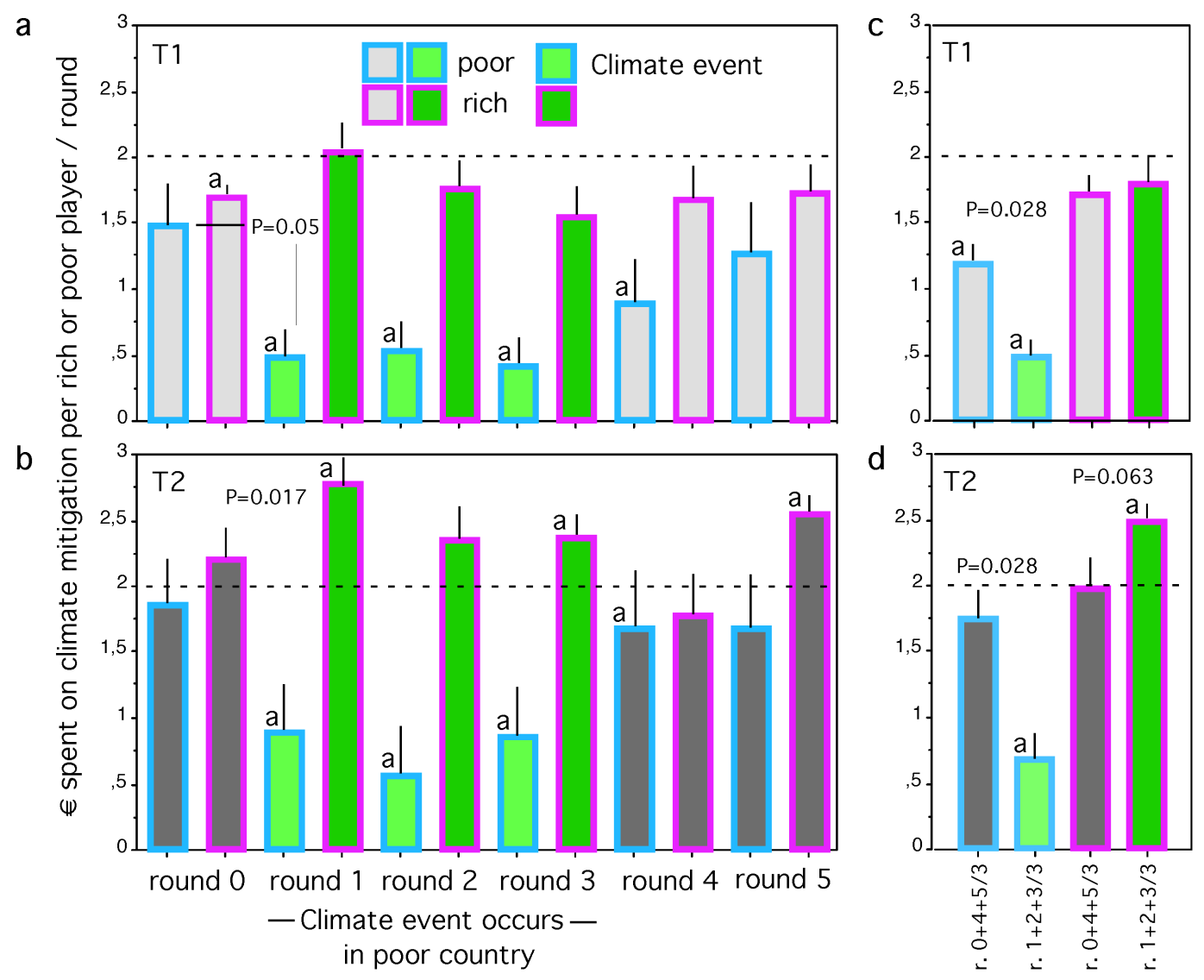
Fig. 4 | Investment in climate mitigation during climate event. Mean (+ s.e.m.) investment of poor and rich inhabitants per group per round in the rounds before and after, and during the three rounds of the first climate event after the Nash distribution has been reached. a, c. in T1, b, $\mathbf{d}$. in $\mathrm{T} 2$. ' a' depicts a significant ( $\mathrm{P}<0.05$, Wilcoxon one-sample test) difference from $€ 2$, the fair share (stippled lines). c shows the investment averaged over the rounds before and after the climate event, and averaged over the three rounds of the climate event, separately for poor and rich participants in T1. d. as in $\mathbf{c}$ but for T2.

\section{The interaction between poverty- and climate-induced migration}

When climate events occur before Nash equilibrium has been reached, there are migrants still fleeing from poverty, and harvest failure due to climate events occurs in addition. We disentangle the two causes of migration by comparing migration-related behaviour before, during and after a climate event in T1 with a similar period before reaching Nash equilibrium in T0. We interpret the difference between T1 and T0 as the pure effect of the climate event, which is zero if the climate event causes no extra migration and measures to block it. 

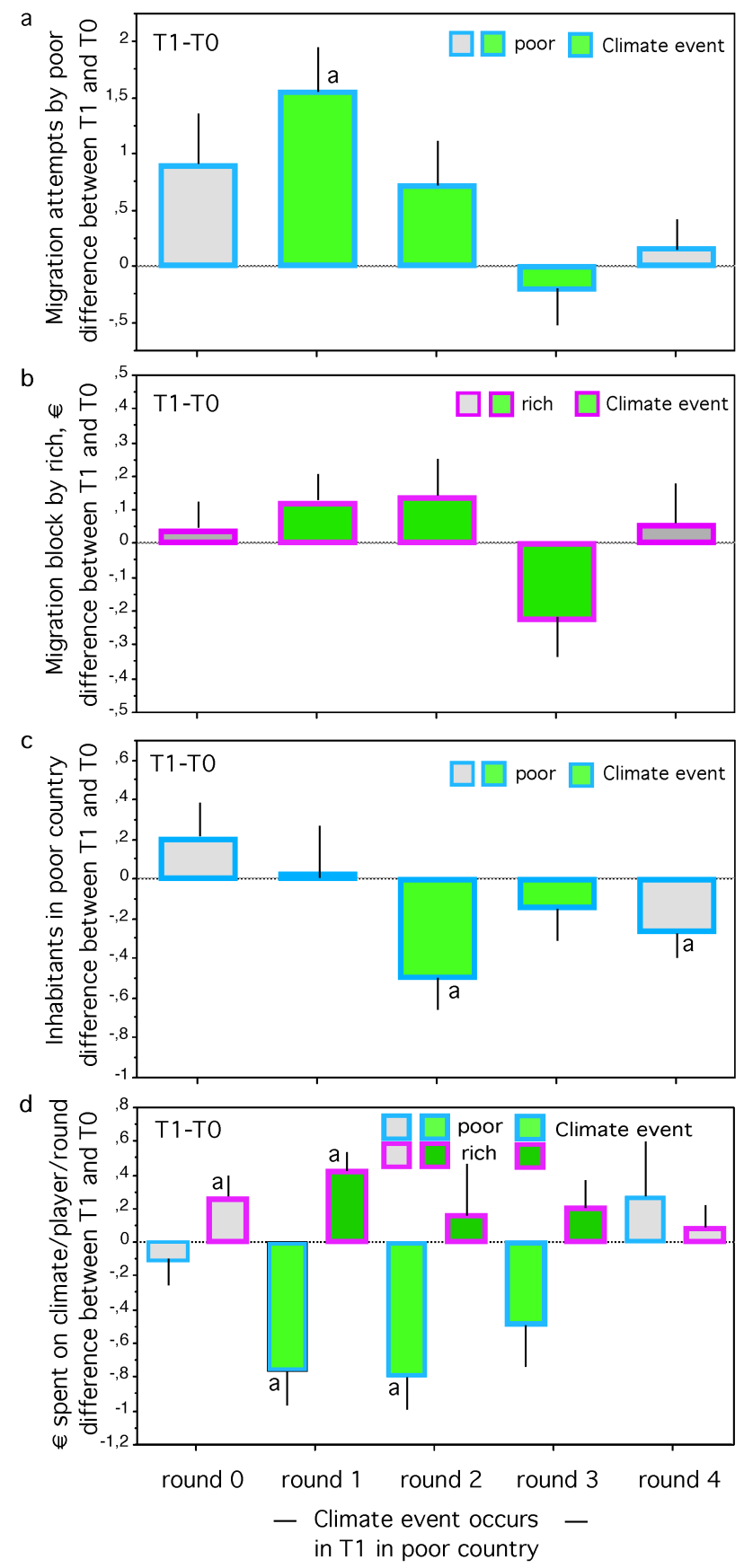

Fig. 5 | Net effect of climate event during poverty migration. Behaviour of poor and rich participants in the round before, the three rounds during, and the round after the climate event in the poor country before Nash equilibrium is reached, meaning poor participants are still migrating to the rich country. Shown is T1-T0, meaning the behaviour in T1 minus the behaviour during the equivalent period in T0. a. migration attempts (mean +/- s.e.m.) per group, b. migration block by rich participants $(€)$ (mean $+/$ - s.e.m.) per group; c. number (mean $+/$ - s.e.m.) of inhabitants in the poor country; d. $€$ (mean $+/$ - s.e.m.) spent on climate mitigation by poor and rich per participant per round; ' $a$ ' depicts significant ( $\mathrm{P}=0.05$ or less) difference from 0 of difference between T1 and T0, P after Wilcoxon one-sample test, see text. 
Migration attempts increase significantly $(\mathrm{P}=0.017, \mathrm{z}=-2.422$, compared to zero difference to T0, Wilcoxon one-sample test) for the first round of the climate event (Fig. 5a). Blocking of migration tends to increase (Fig. 5b). There are significantly $(\mathrm{P}=0.046, \mathrm{z}=-2.000)$ fewer inhabitants in the poor country than in $\mathrm{T} 0$ in the second round of the climate event in T1; an after-effect with a still-decreased number of inhabitants is found in the first round after the climate event $(\mathrm{P}=0.0067, \mathrm{z}=-2.714$, Fig. 5c). The rich increase their contribution to the climate beyond that of $\mathrm{T} 0$ in the first round both before $(\mathrm{P}=0.05, \mathrm{z}=-1.973)$ and of the climate event $(\mathrm{P}=0.017, \mathrm{z}=$ -2.392; Fig. 5d). The poor decrease their contributions to the climate relative to $\mathrm{T} 0$ in the first $(\mathrm{P}=0.033, \mathrm{z}=-2.127)$ and the second round of the climate event $(\mathrm{P}=0.016, \mathrm{z}=-$ 2.413). Thus, a climate event has significant consequences on migration-related behaviour beyond those of poverty only.

\section{The interaction of inhabitants of the poor and the rich country}

We find a significant negative correlation (regression) between average contributions per round of the poor inhabitants and average contributions per round of the rich inhabitants only in $\mathrm{T} 2(\mathrm{P}=0.0001$, R-squared $=0.798)$ (Fig. 6c) but not even a trend in $\mathrm{T} 1(\mathrm{P}=0.84, \mathrm{R}$-squared=0.004) and T0 $(\mathrm{P}=0.997, \mathrm{R}$-squared $=0.001$ (Fig. 6a,b).

However, the result changes qualitatively for those groups in $\mathrm{T} 0$ and $\mathrm{T} 1$ where the rich inhabitants contribute a total of at least the size of the lowest total contribution slightly more than $€ 300$ - of the rich inhabitants in the richer world of T2. Now we find in both T0 and T1 a similarly tight negative correlation as in T2 (Fig. 6d,e). T0 $(\mathrm{P}=0.031, \mathrm{R}$-squared=0.851), T1 $(\mathrm{P}=0.015, \mathrm{R}$-squared $=0.653)$.

Further analysis suggests that it is the poor responding to contributions by the rich and not vice-versa. We have computed the correlation (absolute Spearman's coefficient rho) between contributions of the poor inhabitants with contributions of the rich inhabitants in the previous round. This correlation is in all treatments higher than the reverse correlation (Supplementary Fig. 3). We use absolute coefficients, because we want to know whether and how strongly the poor react to the rich and vice versa, 
irrespective of the direction of the correlation. The correlation coefficient is always highly significant for the poor reacting to the preceding contributions of the rich but only just significant for the rich reacting to the preceding contributions of the poor (Supplementary Fig. 3). The Spearman correlation coefficients are likewise increased as a trend for 'poor reacts to rich' in T0 and T1 for the subsample with higher contributions of the rich, compared the whole sample, corresponding to the difference between Supplementary Figs. 3a and 3d and Supplementary Figs. $3 \mathrm{~b}$ and $3 \mathrm{e}$, respectively. In T1 we find the highest coefficient rho, which is remarkable because in $\mathrm{T} 1$ the poor inhabitants are poorer than those in T0, owing to deficits resulting from climate events.

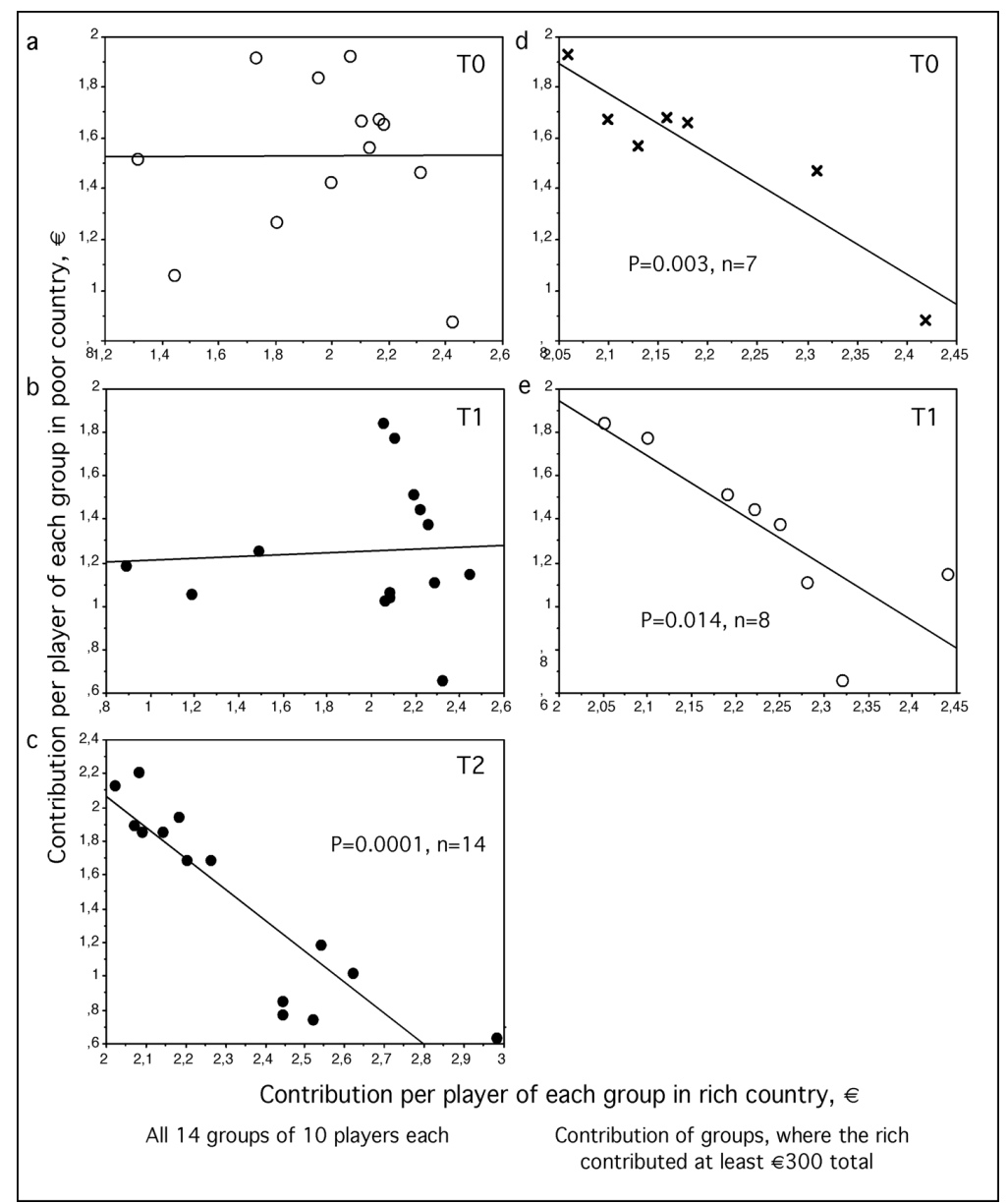

Fig. 6 | Regression of contribution per poor player on contribution per rich player of each group, means of 20 rounds. Line shows linear regression; a. T0, n=13 groups; b. T1, 14 groups; c. T2 $\mathrm{n}=14$ groups; $\mathbf{d}$. T0, $\mathrm{n}=7$ groups where rich players contributed at least $€ 300$ total per group; e. $\mathrm{T} 1, \mathrm{n}=8$ groups where rich players contributed at least $€ 300$ total per group. See text for statistics. 
As Figures $6 \mathrm{~d}$ and 6e suggest, the poor expect contributions from the rich at a certain high level, to which they adjust their own contributions: they fill up the lower of those high contributions more than the higher of those contributions, to help eventually reaching the target sum. This is always successful in T2 and sometimes in T0 and T1. Even in T2 the rich inhabitants never provided the full target sum; it always needs the poor inhabitants' additional contributions. Obviously the rich inhabitants decide on how much to contribute, and if they contribute enough - crossing the threshold of around $€ 300$ that is not part of the design but that instead has emerged from the experiment - the poor inhabitants fill up only and at a rate that appears to be profitable for them to help avoid risking missing the target.

The rich participants providing a large enough contribution to climate mitigation in our experiment can be seen as reducing the gap between the rich and the poor. Such a gap reduction has in a recent game-theoretical analysis ${ }^{36,37}$ been found to help resolve public-goods dilemmas through increased cooperation.

\section{Implications and conclusions}

The external validity of economic laboratory experiments, meaning the applicability of the conclusions to the real world, always harbours substantial uncertainty. To increase external validity we assured the students that all the money they pay into the climate account is used to purchase an advertisement on 'how to mitigate climate change' published in one of two German newspapers - the 'Hamburger Abendblatt' and the 'Kieler Nachrichten' (see Supplementary Information), as a real albeit small contribution to help reducing climate change with their money. We assured that the text, date of publication and cost of the adverts are published in the Supplementary Information of the final article. Moreover, the global challenge of averting dangerous anthropogenic climate change shares enough characteristics with the collective-risk social dilemma under heterogeneous wealth distribution represented in our experiment that a number of implications can be inferred.

First, we have seen that migration instigated by poverty or by a climate extreme event cannot in the long run be prevented. Our relatively rich participants are most effective at blocking migration right when a climate event occurs in the poor country, but 
overall the free-riding among the rich when cooperation would have been required to prevent migration suggests that climate-induced migration to richer countries is all but inevitable.

Second, the willingness of our rich participants to contribute to climate mitigation is largest right when the poor are hit by a climate extreme event, exacerbating their poverty. Our rich participants appear to anticipate that then the poor participants are even less able and willing to contribute to the collective good and make up for some, but not all, of the shortfall. The implication - tragedy in poor countries enhances the climate mitigation effort by the rich countries - bears a strong and for some perhaps unpalatable Machiavellian touch.

And third, the unexpected emergence of a threshold - a minimum contribution by the rich above which the poor are willing to compensate some reduced effort by the rich toward the mitigation target - suggests that global cooperation might be within reach, as long as the economically powerful are perceived as pulling their weight in the global effort to avert dangerous climate change.

\section{Methods}

\section{Experimental design}

Experiments were conducted in November and December 2017 with a total of 410 undergraduate students from the Universities of Kiel and Hamburg, Germany. The students received a show up fee of $€ 10$ each and participated in 41 experimental sessions with 10 participants each in a computerized experiment using the software ztree $^{39}$. The participants were separated by opaque partitions and each had a computer, on which they received the instructions for the experiment and with which they communicated their decisions. Participants were randomly allocated to experimental groups, were anonymous throughout the whole experiment and made their decisions under a neutral pseudonym.

\section{Treatments}

We had a control treatment T0 with 13 groups, for treatments T1 and T2 we had 14 
groups each. The participants interacted in a variant of the 'collective-risk social dilemma' game ${ }^{14}$, they received an initial endowment and were asked, in each of 20 rounds, to contribute either $0, € 2$ or $€ 4$ from this endowment into a 'climate account'. A participant could invest only if her/his account contained sufficient money. At the end of round 20, the game software checked whether total contributions of all group members matched (or exceeded) the target sum of $€ 400$. If that was the case, i.e. each group member had paid $€ 2$ per round on average, participants received the money in their account in cash in a way that maintained the participants' anonymity. If the collective target was not reached, participants lost their remaining money with $90 \%$ probability. At the start of each session 5 participants were randomly assigned to a rich country, 5 to a poor country. Each of the 5 rich participants received an endowment of $€ 40$, each of the 5 poor received $€ 20$ on their account. The decisions of all 10 participants were shown under their pseudonyms to all participants after each round. Pseudonyms were moons of our solar system: Ananke, Telesto, Despina, Japetus, Kallisto, Metis, Telesto, Galatea, Nereid, Elara, Vestia. At the start the five rich earned twice the harvest per round in the rich country (€3.00 each in T0 and T1, $€ 6.00$ each in T2) as the five poor in the poor country ( $€ 1.50$ in $\mathrm{T} 0$ and $\mathrm{T} 1, € 3.00$ in T2). (Supplementary Table 1). Each participant had to pay $€ 0.50$ in each round for 'living expenses'.

\section{Migration}

See main text for details.

\section{Climate events}

See main text for details.

For a detailed description of each treatment, a translation of the instructions to participants is provided in the Supplementary Information.

\section{Statistics}

All p-values are two-tailed. Except for regression analysis we use non-parametric statistic throughout. 


\section{Reporting Summary}

Further information on research design is available in the Nature Research Reporting Summary linked to this article.

\section{Data availability}

The dataset generated and analysed during the current study will be available in https://pure.mpg.de/pubman/faces/ViewItemFullPage.jsp?itemId=item_3217143

\section{Code availability}

The data analysis code is available from the corresponding author on request.

\section{References}

1. Adger, W.N. et al. Human security. In: Climate Change 2014: Impacts, Adaptation, and Vulnerability. Part A: Global and Sectoral Aspects. Contribution of Working Group II to the Fifth Assessment Report of the Intergovernmental Panel on Climate Change [Field, C.B. et al. (eds.)]. Cambridge University Press, Cambridge, United Kingdom and New York, NY, USA, pp. 755-791 (2014).

2. Winsemius, H. C., Jongman, B., Veldkamp, T. I. E., Hallegatte, S., Bangalore, M. \&Ward, P. J. Disaster risk, climate change, and poverty: assessing the global exposure of poor people to floods and droughts. Environm. \& Development Economics 23, 328-348 (2018).

3. Hallegatte, S., Fay, M. \& Barbier, E. B. Poverty and climate change: an introduction. Environm. \& Development Economics 23, 217-233 (2018).

4. Hansen, J. et al. Climate risk management and rural poverty reduction. Agricultural Systems 172, 28-46 (2019).

5. Zander K. K., Surjan, A. \& Garnett, S. T. Exploring the effect of heat on stated intentions to move. Climatic Change 138, 297-308 (2016).

6. Shayegh, S. Outward migration may alter population dynamics and income inequality. Nat. Clim. Change 7, 828-832 (2017). 
7. McLeman, R. International migration and climate adaptation in an era of hardening borders. Nat. Clim. Change 9, 911-918 (2019).

8. Cattaneo, C. \& Peri, G. The migration response to increasing temperatures. J. Development Economics 122, 127-146 (2016).

9. Ravenstein, E. G. The laws of migration. J. Roy. Statistical Soc. 48, 167-235 (1885).

10. Bourne, S. Discussion of Mr. Ravenstein's paper. J. Roy. Statistical Soc. 52, 303 (1889).

11. Lee, E. S. A Theory of migration. Demography 3, 47-57 (1966).

12. Porumbescu, A. Defining the new economics of labor migration theory boundaries: a sociological-level analysis of international migration. RSP 45, 55-64 (2015).

13. Stark O. The migration of labour. Cambridge, Basic Blackwell (1991).

14. Stark, O. \& Bloom, E. D. The new economics of labor migration. Amer. Economic Rev. 75, 173-178 (1985).

15. Black, R., Adger, W. N., Arnell, N. W., Dercon, S., Geddes, A. \& Thomas, D. S. G. The effect of environmental change on human migration. Global Environmental Change 215, S3-S11 (2011).

16. McLeman, R. Settlement abandonment in the context of global environmental change. Global Environmental Change 21, S108-S120 (2011).

17. Chen, J. \& Mueller, V. Coastal climate change, soil salinity and human migration in Bangladesh. Nat. Clim. Change 8, 981-985 (2018).

18. Mastrorillo, M., Licker, R., Bohra-Mishra, P., Fagiolo, G., Estes, L. D. \& Oppenheimer, M. The influence of climate variability on internal migration flows in South Africa. Global Environmental Change 39, 155-169 (2016).

19. Böhm, R., Theelen, M. M. P., Rusch, H. \& Van Lange, P. A. M. Costs, needs, and integration efforts shape helping behaviour toward refugees. Proc. Natl. Acad. Sci. U.S.A. 115, 7284-7289 (2018).

20. Abel, G. J., Brottrager, M., Guaresma, J. C. \& Muttarak, R. Climate, conflict and forced migration. Global Environmental Change 54, 239-249 (2019).

21. Smith, V. L. Papers in Experimental Economics. Cambridge University Press, (2010).

22. Milinski, M., Sommerfeld, R. D., Krambeck, H.-J., Reed, F. A. \& Marotzke, J. The collective-risk social dilemma and the prevention of simulated 
dangerous climate change. Proc. Nat. Acad. Sci. U.S.A. 105, 2291-2294 (2008).

23. Milinski, M., Röhl, T. \& Marotzke, J. Cooperative interaction of rich and poor can be catalyzed by intermediate climate targets. Clim. Change 109, 807-814 (2011).

24. Tavoni, A., Dannenberg, A., Kallis, G. \& Löschel, A. Inequality, communication, and the avoidance of disastrous climate change in a public goods game. Proc. Nat. Acad. Sci. U.S.A. 108, 11825-11829 (2011).

25. Chen, X., Szolnoki, A. \& Perc, M. Risk-driven migration and the collectiverisk social dilemma. Physical Review E 86, 036101-1-8 (2012).

26. Jacquet, J., Hagel, K., Hauert, C., Marotzke, J., Röhl, T. \& Milinski, M. Intraand intergenerational discounting in the climate game. Nat. Clim. Change 3, 1025-1028, DOI: 10.1038/NCLIMATE2024 (2013).

27. Burton-Chellow, M. N., May, R. M. \& West, S. A. Combined inequality in wealth and risk leads to disaster in the climate change game. Clim. Change 120, 815-830 (2013).

28. Abu Chakra, M. \& Traulsen, A. Under high stakes and uncertainty the rich should lend the poor a helping hand. J. Theor. Biol. 341, 123-130 (2014).

29. Milinski, M., Hilbe, C., Semmann, D., Sommerfeld, R., \& Marotzke, J. Humans choose representatives who enforce cooperation in social dilemmas through extortion. Nature Communications 7:10915 (2016|) | DOI: 10.1038/ncomms10915 |www.nature.com/naturecommunications.

30. Hagel, K., Milinski. \& Marotzke, J. The level of climate-change mitigation depends on how humans assess the risk arising from missing the $2^{0} \mathrm{C}$ target. Palgrave Communications 3:17027 (2018). doi10.1057/palcomms.2017.27.

31. Schneider, S. H. What is 'dangerous climate change'? Nature 411, 17-19 (2001).

32. Meinshausen, M. et al. Greenhouse-gas emission targets for limiting global warming to 2 C. Nature 458, 1158-1162 (2009).

33. Peters, G. P. et al. The challenge to keep global warming below $2^{\circ} \mathrm{C}$. Nat. Clim. Change 3, 4-6 (2013).

34. IPCC. Climate Change 2014: Synthesis Report. Contribution of Working Groups I, II and III to the Fifth Assessment Report of the Intergovernmental Panel on Climate Change (IPCC, 2014). 
35. Hardin, G. The tragedy of the commons. Science 162, 1243-1248 (1968).

36. Gao, B., Liu, X., Hou, S., Jia, D. \& Du, M. Resolving public goods dilemma by giving the poor more support. Applied Mathematics and Computation 362 , 124529 (2019).

37. Gächter, S., Mengel, F., Tsakas, E. \& Vostroknutov A. Growth and inequality in public good provision. J. Public Economics 150, 1-13 (2017).

38. Sokal, R. R. \& Rohlf, F. J. Biometry Second edition, W. H. Freeman and Company, New York, (1981).

39. Fischbacher, U. z-Tree: Zurich toolbox for ready-made economic experiments. Experimental Economics 10, 171-178 (2007). doi: 10.1007/s10683-006-9159

\section{Acknowledgements}

We thank the students from the universities of Hamburg and Kiel for their participation, H. Brendelberger and S. Dobler for logistic support, this study was supported by the Max Planck Society for the Advancement of Science.

\section{Author Contributions}

M.M. conceived the study, M.M. and J.M. designed the study, D.S. wrote the z-tree program, D.S. and M.M. performed the research, M.M. analysed the data, M.M. and J.M. wrote the paper, and all authors revised the manuscript.

\section{Corresponding author}

Correspondence to M. Milinski

\section{Ethics declarations}

\section{Competing interests}


The authors declare no competing interests.

\section{Supplementary Information}

Supplementary Table 1, Supplementary Figs. 1-3, Nash Equilibria with references, Ethics statement, Advertisement in daily newspapers of those University cities where experiments were performed, Instructions for participants

\begin{tabular}{|c|c|c|c|c|c|c|c|c|c|c|c|}
\hline $\mathrm{N}$ in rich habitat & & 1 & 2 & 3 & 4 & 5 & 6 & 7 & 8 & 9 & 10 \\
\hline harvest/N, $€$ & & 4.00 & 3.75 & 3.50 & 3.25 & 3.00 & 2.75 & 2.50 & 2.25 & 2.00 & 1.75 \\
\hline $\mathrm{N}$ in poor habitat & 10 & 9 & 8 & 7 & 6 & 5 & 4 & 3 & 2 & 1 & \\
\hline harvest/N, $€$ & 0.25 & 0.50 & 0.75 & 1.00 & 1.25 & 1.50 & 1.75 & 2.00 & 2.25 & 2.50 & \\
\hline
\end{tabular}

(b) High overall harvest (T2):

$\mathrm{N}$ in rich habitat

harvest $/ \mathrm{N}, €$

8.00

$\begin{array}{rr}2 & 3 \\ 7.50 & 7.00\end{array}$

4
6.50

5
6.00

6
5.50

$\begin{array}{rrrr}7 & 8 & 9 & 10 \\ 5.00 & 4.50 & 4.00 & 3.50\end{array}$

$\mathrm{N}$ in poor habitat 10

$\begin{array}{rrrr}9 & 8 & 7 & 6 \\ 1.00 & 150 & 2.00 & 250\end{array}$

5
3.00

$\begin{array}{rrrr}4 & 3 & 2 & 1 \\ 3.50 & 4.00 & 4.50 & 5.00\end{array}$

Extended Data Fig. $1 \mid$ Harvest per inhabitant per round $(€)$. in the rich country and the poor country dependent on the number of inhabitants. (a) with

low overall harvest in $\mathrm{T} 0$ and $\mathrm{T} 1,(\mathrm{~b})$ with high overall harvest in $\mathrm{T} 2$.

Nature

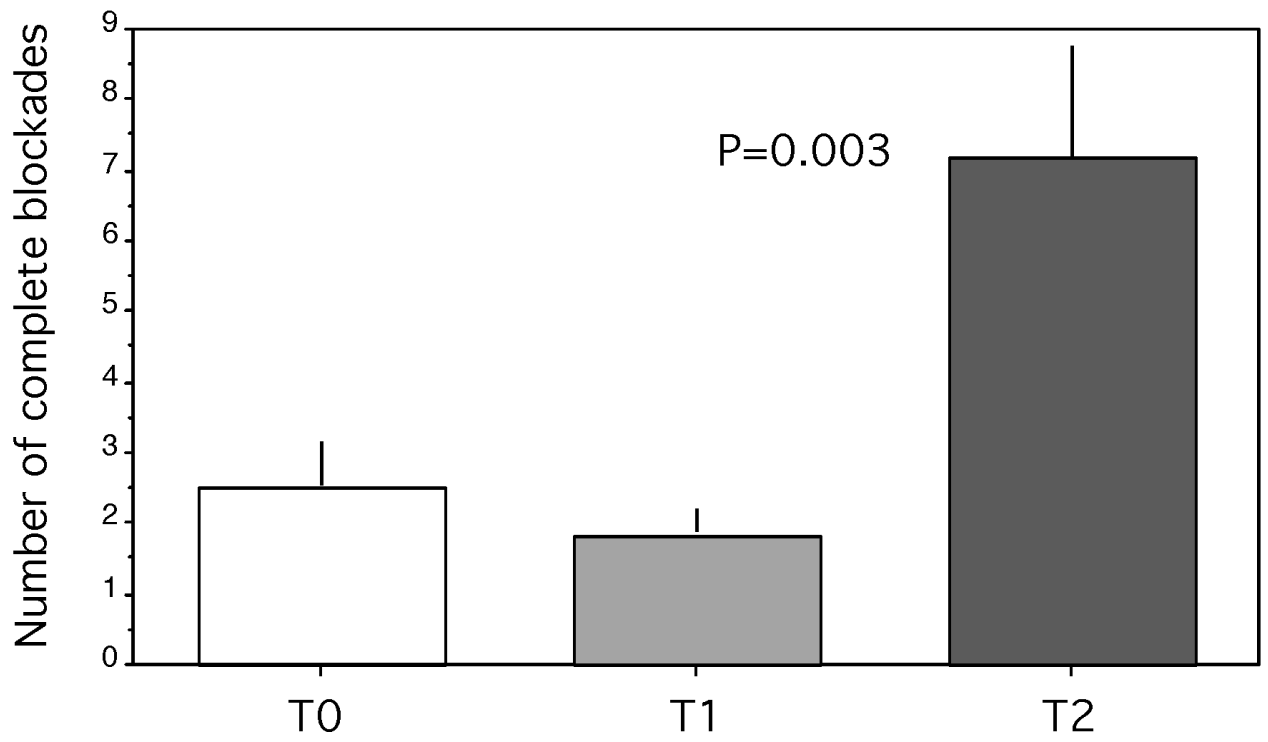


Extended Data Fig. $2 \mid$ Number of complete blockades. Mean + s.e.m. per group in T0, T1 and T2. $\mathrm{P}$ after Mann-Whitney U-test, $\mathrm{n} 1=14, \mathrm{n} 2=14, \mathrm{z}=-2.955$. Effective blockings (mean \pm s.e.m.) per group: $2.5 \pm 0.7$ in $\mathrm{T} 0,1.8 \pm 0.2$ in $\mathrm{T} 1$, and $7.1 \pm 1.7$ in $\mathrm{T} 2$, respectively.

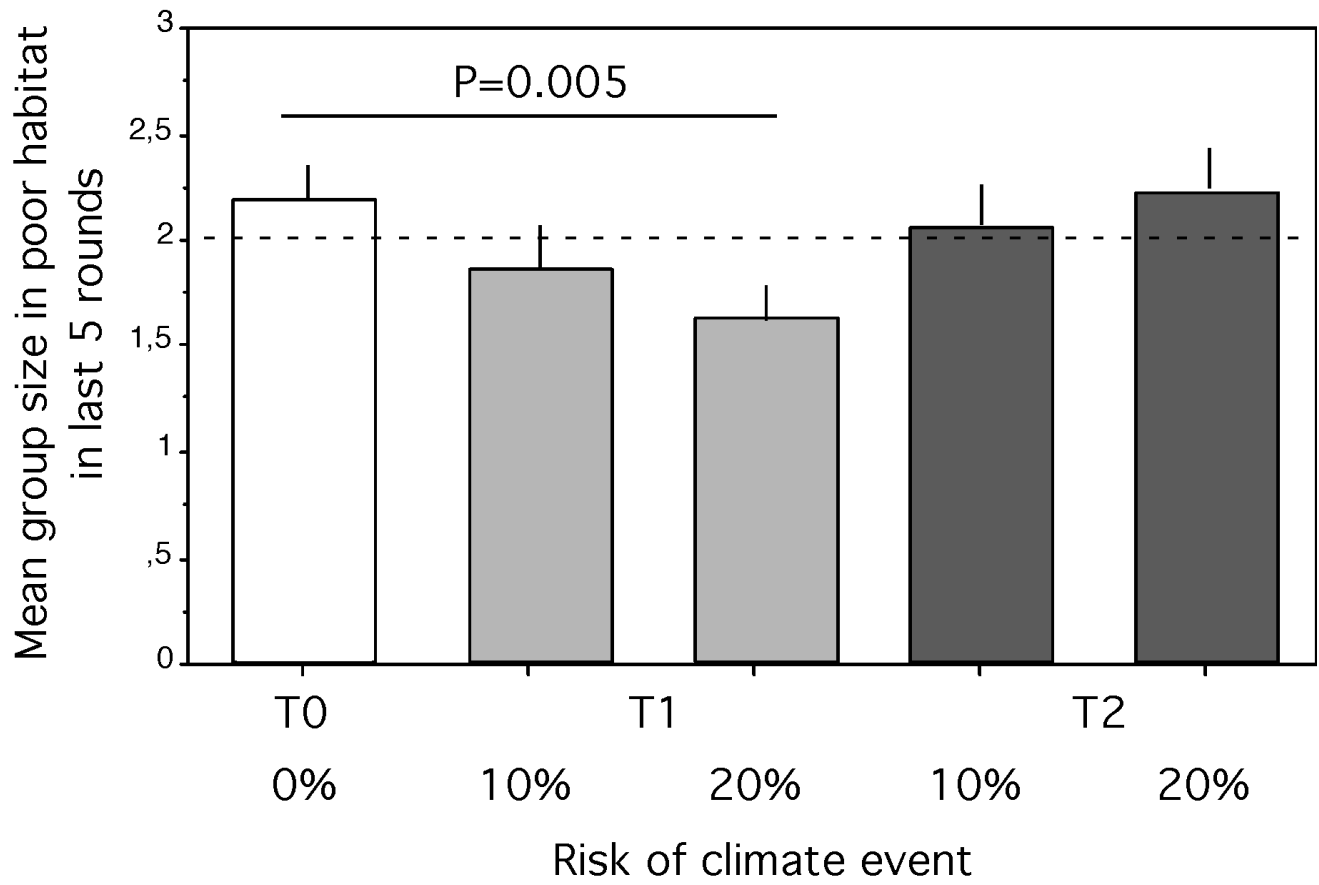

Extended Data Fig. 3 | Risk of climate event. Group size per group (mean \pm s.e.m.) in the last 5 rounds per round in the poor country in $\mathrm{T} 0$, in $\mathrm{T} 1$ and $\mathrm{T} 2$ dependent on the risk of a climate event to occur of either $0 \%, \mathrm{n}=13,10 \%, \mathrm{n}=7$, or $20 \%, \mathrm{n}=7$, per round. There are fewer inhabitants in the poor country during the last five rounds with increasing risk of climate events $(\mathrm{n}=3$ treatments, $\mathrm{P}=0.005, \mathrm{~h}=10.534$, Kruskal-Wallis test). 


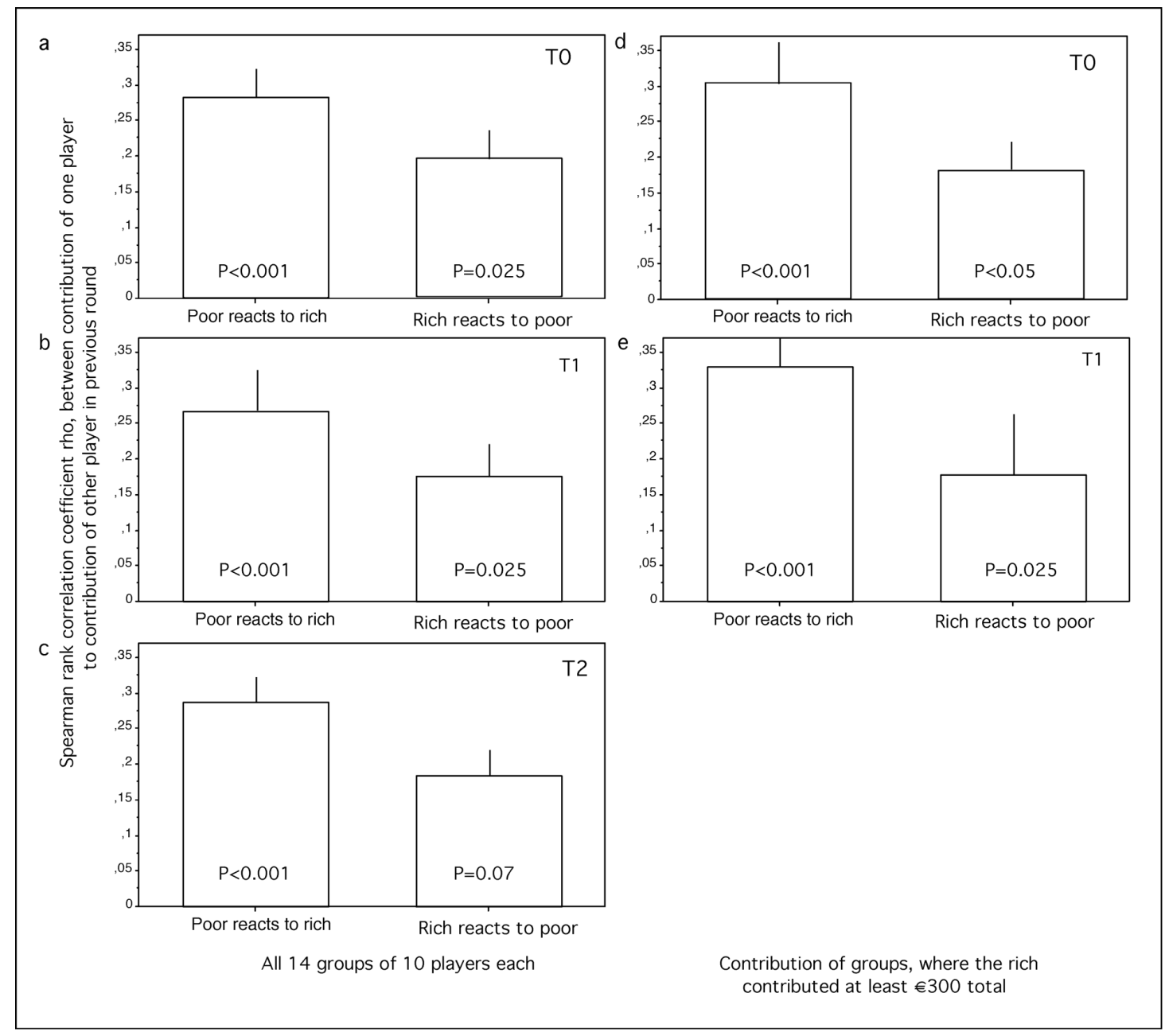

Extended Data Fig. $4 \mid$ Absolute Spearman rank correlation coefficients. rho, mean + s.e.m., between contributions of one class of players to contributions of the other class of players in previous round over 19 rounds per group. Poor player reacts to rich player's contribution in previous round, rich player reacts to poor player's contribution in previous round; a. T0, $\mathrm{n}=$ 13 groups of 10 players each, b. T1, $n=14$ groups of 10 players each, c. T2, $n=14$ groups of 10 players each; $d$. T0, 7 groups of 10 players each, where rich players contributed at least $€ 300$ total per group, e. T1, 8 groups of 10 players each, where rich players contributed at least $€ 300$ total per group. $P$ calculated from Fisher combination test 41 , a. combining $P$ values from each of 13 (T0), b, c. of 14 (T1, T2), d. of 7 (T0), e. of 8 (T1) independent groups of 10 players each. For each group the Spearman correlation coefficient rho was calculated from 19 rounds, providing a single p-value.

41. Sokal, R. R. \& Rohlf, F. J. Biometry 2nd edn (W. H. Freeman, 1981). 